\title{
VISÕES DO PARAÍSO: O DISCURSO OFICIAL BRASILEIRO SOBRE ECOLOGIA E A EXALTAÇÃO DAS BELEZAS NATURAIS DAAMAZÔNIA
}

Antonio Teixeira de Barros*

\begin{abstract}
Resumo: Analisa, do ponto de vista social e político, o discurso oficial brasileiro sobre meio ambiente, no período de 1972 (Eco 72) a 1992 (Eco 92), no que se refere à Amazônia. Resgata a questão do mito da visão do paraíso, estudada pelo sociólogo brasileiro Sérgio Buarque de Holanda, para explicar as tendências atuais do discurso governamental de caráter marcadamente ufanista sobre a Amazônia brasileira. Tal opção deve-se à constação de que, em diversos momentos, o ufanismo é utilizado pelo Estado como estratégia discursiva para se justificar diante da comunidade internacional e da própria sociedade brasileira, como forma de amenizar as pressões internacionais e as reivindicações ambientalistas internas. ${ }^{1}$
\end{abstract}

PALAVRAS-CHAVE: Meio ambiente no Brasil, Discurso oficial brasileiro sobre meio ambiente, Amazônia, Sérgio Buarque de Holanda, Pensamento social brasileiro.

ABSTRACT: This essay analyzes the Brazilian official discourse on environment, in the period from 1972 (“Eco 72") to 1992 ("Eco 92"), in when it refers to Brazilian Amazon. It rescues the myth of the paradise's vision, studied by Sérgio Buarque de Holanda, to explain the current tendencies in the government's discourse with character remarkably patriotic boasting on Brazilian Amazon. Such option is explain by the fact ed for the verification that, in several moments, the patriotic overoptimism is used by the State as a discoursive justification strategy for the international community and for the Brazilian society, as form of livening up the international pressures and internal claims.

KEY WORDS: Environment in Brazil, Brazilian official discourse on environment, Brazilian Amazon, Sérgio Buarque de Holanda, Brazilian social thought.

\footnotetext{
* Instituto de Educação Superior de Brasília (antonio.barros@camara.gov.br).

${ }^{1}$ Elaborado com base no mesmo corpus utilizado para a pesquisa que deu origem à tese de doutoramento do autor, intitulada "Atores e discursos ecológicos no Brasil: ciência, estado e imprensa (1972-92)", apresentada ao Departamento de Sociologia da Universidade de Brasília, sob a orientação da Profa. Dra. Fernanda Sobral, em 1999.
} 


\section{INTRODUÇÃO}

O objetivo geral deste trabalho é analisar a presença do mito do "paraíso terreal" no discurso oficial brasileiro acerca da Amazônia, no âmbito da questão ambiental nos fóruns internacionais e nacionais de discussão do assunto, no período de 1972 (Eco 72) a 1992 (Eco 92). Para tanto, utilizamos como base o pensamento do historiador brasileiro Sérgio Buarque de Holanda, em seu livro Visão do Paraíso (1994), resultado de sua tese de doutoramento. Trata-se de obra ensaística, na qual o autor analisa o imaginário do colonizador português sobre as belezas nativas da terra brasilis.

Em termos de objetivos específicos, propomo-nos a verificar como se dá a representação da Amazônia brasileira na atualidade, confrontando essa representação com as antigas "visões do paraíso", uma representação que existiu no imaginário social que precedeu a descoberta do Brasil e se perpetuou por alguns séculos, como foi documentado pelos cronistas coloniais e os antigos brasilianistas, conforme assinala Sérgio Buarque de Holanda, na obra mencionada.

Entendemos por discurso oficial sobre meio ambiente o que é produzido por organismos governamentais, institucionalizando uma fala consensual sobre a problemática ecológica. Segundo Carvalho, tal discurso regulamenta, estabelece metas e produz o fato ecológico, com base em idéias genéricas e fluidas como bem-estar e qualidade de vida:

Esses termos são usados como se tivessem um sentido unívoco. No entanto, o que é melhorar, do ponto de vista desse discurso? O que é bem-estar ou uma vida de qualidade na sociedade de consumo? Sabemos como esses signos são manejados, associando-se a produtos, projetos e condutas, que precisam ser vendidos [...] Assim, esse discurso nomeia como bom um certo modelo de desenvolvimento e esta é a sua medida para a melhoria e o bemestar. Clama pela preservação da natureza, comprometido de antemão com as regras do capitalismo industrial e do consumo. ${ }^{2}$

2 Isabel Cristina M. Carvalho, "Ecología: um campo estratégico", Revista de Cultura Vozes, vol. 84, núm. 2, Petrópolis, marzo-abril, 1990, pp. 234-241, p. 237. 
A escolha do tema decorre da constatação, em outra pesquisa, ${ }^{3}$ de que o ufanismo - isto é a exaltação das belezas naturais e de uma visão paradisíaca da Amazônia - é uma das marcas do discurso oficial brasileiro sobre meio ambiente no Brasil. Diante disso, decidimos utilizar alguns dados do corpus da pesquisa original, mas com um novo propósito: desenvolver uma análise, sob a ótica do pensamento social brasileiro, mais especificamente, de Sérgio Buarque de Holanda.

O corpus utilizado na pesquisa original compreende textos oficiais-discursos, documentos e publicações técnicas que expressam a postura oficial do Governo brasileiro em relação ao assunto. Estão inclusos nesse rol os pronunciamentos em fóruns internacionais e nacionais, textos-base dos planos nacionais de desenvolvimento (PND's) e desenvolvimento científico e tecnológico (PNDCT'S).

O ufanismo, que se manifesta na constante exaltação dos atributos naturais do país, principalmente da Amazônia, é uma constante no conjunto dos textos coletados. Em todas as ocasiões, o tom ufanista é utilizado, mesmo quando o tema discutido é negativo, como no caso de devastação, queimadas, desastres naturais e outros assuntos negativos. Como ressalvas, sempre são postos em relevo aspectos positivos, como potencial turístico, as belezas naturais etc.

\section{A AMAZÔNIA E AS VISÕES DO PARAÍSO}

Em Visão do Paraíso (1969), Sérgio Buarque de Holanda analisa os motivos edênicos que povoaram o imaginário sobre o descobrimento do Brasil e as primeiras narrativas dos colonizadores e expedicionários sobre os trópicos brasileiros. A exuberância e a prodigalidade da natureza nesses relatos, aguçou o imaginário de povos distantes, levando-os a construir representações edênicas sobre as novas terras, imaginando ser as mesmas remanescentes do paraíso terreal, sede do Jardim do Éden. As

\footnotetext{
${ }^{3}$ A pesquisa original propôs-se a caracterizar o discurso oficial brasileiro sobre meio ambiente, no período de 1972-1992.
} 
narrativas produzidas, desde cedo, tornaram-se manifestações arquetípicas de um discurso que remetia literalmente ao mito do paraíso terreal. É necessário esclarecer que as terras brasileiras não foram as únicas a despertarem esse imaginário edênico. O próprio Sérgio Buarque de Holanda demonstra que outras paragens, partes da geografia fantástica da América, como o Perú e principalmente todas as adjacências da Amazônia foram objeto desse imaginário edênico.

$\mathrm{O}$ autor questiona se dos mitos geográficos difundidos na era dos grandes descobrimentos marítimos é possível se tirar conclusões válidas para um relance sobre a formação brasileira, especialmente durante o período colonial. O que ocorre, na realidade, conforme o autor, é que os descobridores, povoadores, aventureiros e cronistas encontraram aqui uma espécie de cenário ideal, idílico, paradisíaco, que correspondia a uma cosmovisão moldada em experiências, mitologias ou nostalgias ancestrais, que correspondia à idéia de um Eldorado.

E destaca ainda que os portugueses não foram os únicos a construírem essas visões do paraíso terreal, pois se trata de uma cosmovisão universal, existente em quase todas as culturas. Basta lembrarmos a teoria do mito do eterno retorno, de Mircea Eliade. ${ }^{4}$ Entretanto, os relatos e crônicas sobre o descobrimento do Brasil ampliam de forma grandiosa essa visão paradisíaca. Movidos mais por uma visão fantástica do que pragmática, os cronistas quinhentistas chegam a oferecer demonstrações verdadeiramente extasiadas e enamoradas, frente à visão da exuberante natureza encontrada nas novas terras tropicais.

Todo o universo lendário e mítico em torno do paraíso terreal remete, ainda às conquistas castelhanas, as quais suscitaram

eldorados, amazonas, serras de prata, lagoas mágicas, fontes de juventude [...] de ilhas encantadas, fontes mágicas, terras de luzente metal, de homens e monstros discrepantes da ordem natural, de criações prazíveis ou temero-

${ }^{4}$ Conforme Mircea Eliade, O mito do eterno retorno, Lisboa, Edições 70, 1969 (Coleção Perspectivas de Homen). A teoria do eterno retorno refere-se ao mito do começo (comsmogonia) e do fim do mundo (escatologia). 
sas, com que os novelistas incessantemente deleitavam um público sequioso de gestos guerreiros e fantásticos sortilégios, rapidamente se foram povoando as conquistas de Castela. E não é menos flagrante aqui o contraste que se oferece entre elas e as regiões do mesmo continente destinadas à Coroa lusitana. ${ }^{5}$

Mas as narrativas mais férteis foram aquelas que exaltavam as grandezas do Brasil: a geografia fantástica, a imensidão territorial, a fauna, a vegetação, a imensa diversidade de frutas, flores e belezas mil dos campos. O próprio Hino Nacional Brasileiro exalta esses atributos singulares do país. Foi exatamente a região da Amazônia, mais especificamente o chamado Grão-Pará que mais despertou a atenção dos cronistas, como documenta Sérgio Buarque de Holanda:

Não lhe custaria mesmo acreditar, em face das muitas maravilhas que escreveram sobre o Grão-Pará, e amparado naquela 'fé comum da tradição humana', na possibilidade de ter sido ali planto por Deus o próprio Paraíso Terreal [grifo nosso]. Isso mesmo há de dizê-lo em alguns parágrafos de suas Notícias Curiosas, onde formula e responde à pergunta sobre se o mesmo Paraíso não seria a América. Consultados alguns dos mestres de Lisboa e outros das Universidades de Évora e Coimbra, todos foram acordes em que não havia nada de definido em matéria de fé sobre o sítio do Éden, e que o autor não afirmava, tão-somente lembrava, a probabilidade de achar-se na América, isto é, no Brasil deixando essa probabilidade ao critério de quem o lesse. ${ }^{6}$

Mais especificamente, destaca o autor que não faltaram argumentos, apoiados em escritos de teólogos antigos e modernos, a favor da crença dos que situassem o sagrado horto no coração do Brasil, de preferência na Amazônia. Muitos daqueles teólogos,

${ }^{5}$ Sérgio Buarque de Holanda, Visão do paraíso: os motivos edênicos no descobrimento e colonização do Brasil, $2^{\mathrm{a}}$ ed., São Paulo, Compañía Editora Nacional, 1969, pp. 126127.

${ }^{6}$ Ibid., p. 135. 
entre eles o próprio $\mathrm{S}$. Tomás de Aquino, teriam colocado o paraíso debaixo da linha equinocial, cuidando que era a parte do mundo mais temperada, mais deleitável e mais amena para a perfeita habitação dos homens. Sucede ainda que entre as regiões equatoriais, nenhuma [...] tinha em si as bondades que mostra o Brasil. E como lhe parecesse indiscutível, de acordo com a melhor filosofia, que da excelência das propriedades se colhe a do ser, passa a sumariar logamente as que fazem a suma perfeição da América lusitana. ${ }^{7}$

Esses teólogos ressaltavam quatro propriedades que, necessariamente, lhes pareciam essenciais para a existência do paraíso na terra. A primeira está nisto, "que se há de vestir de verde, com erva, pasto e arvoredo de vários gêneros". A segunda, “que gozará de bom clima, boas influências do céu, do sol, da lua, das estrelas". A terceira propriedade: "que sejam abundantes suas águas em peixes, e seus ares em aves". Que se produza "todos os gêneros de animais e bestas da terra" constitui a quarta propriedade. Segundo o cronista da Companhia de Jesus, P. Simão de Vasconcelos ${ }^{8}$ tudo consta do divino texto da criação do mundo.

De todos os pontos cogitados, segundo o cronista jesuíta, somente o Brasil atendia a todas essas propriedades, "em grau eminente". Daí a razão que o leva a concluir "estar nestas partes o mesmo deleitoso jardim em que pusera Deus os nossos primeiros pais, se não um símile ou cópia dele, já que faziam vantagem aos fabulosos Campos Elísios, ou aos jardins suspensos, ou ainda à Atlândida e, sem dúvida, à Taprobana, de ares tão infensos à saúde dos homens, conforme já o tinham podido experimentar os próprios portugueses, ainda que houvesse quem, impensadamente, visse ali a pátria verdadeira de Adão". 9

A questão da água, nesse contexto mítico, merece atenção especial, por se tratar de um símbolo que remete a várias ordens de significado. A primeira diz respeito ao elemento próprio da cosmogonia, por ser considerada a fonte da criação. Diz o Gênesis (1:1-2) que "No princípio

${ }^{7}$ Ibid., p. 138.

${ }^{8}$ Crônica da Companhia de Jesus, citada por Buarque de Holanda, op. cit., p. 138.

${ }^{9}$ Ibid., pp. 138-139. 
criou Deus os céus e a terra. E a terra era sem forma e vazia; e havia trevas sobre a face do abismo; e o Espírito de Deus se movia sobre as águas[...]". A água, constitui, portanto, fonte de criação, fonte de vida, elemento central no mito da criação do mundo. ${ }^{10}$

No caso da Amazônia, o mito da cosmogonia é ressaltado pela forte presença do elemento água, sobretudo pela importância dos peixes, da fauna e flora aquáticas, que assinalam a prodigalidade desse elemento. Isso faz com que o espaço amazônico seja vinculado a uma espécie de criador, de renovador de todo o Cosmo. Esta renovação tem lugar, por excelência, no período da enchente e da vazante dos rios, "quando se inaugura um novo ciclo temporal e a identificação deste espaço, com a origem do mundo, é uma reiteração da cosmogonia, como se a cada novo ciclo das águas a criação recomeçasse. [...] Na Amazônia está o começo do mundo, pois a água é criação, é gênese, é começo[...]". ${ }^{11} \mathrm{O}$ mito da água remete a outro mito: o de Narciso. A água se torna espelho que reflete a imagem do próprio homem - ou da própria natureza. A imensidão das águas reflete e duplica, como um espelho, a exuberância do eldorado amazônico.

Uma das hipóteses que mais se destacavam quanto à situação do paraíso terreal no Brasil, dizia respeito à origem da chamada "árvore da ciência do bem e do mal", que não produziria maçãs, nem figo, mas maracujá, a "granadilha" dos castelhanos, o qual "na aparência, na cor, no sabor e em outras qualidades, é muito conforme ao que dizem os expositores do pomo que foi instrumento de nossa perdição e feitiço dos olhos de Eva". ${ }^{12}$

Segundo essa visão, o homem teria nascido na América do Sul. Daí a razão para sua forma geográfica, como o desenho de um coração. E

${ }^{10} \mathrm{E}$ isso não ocorre apenas na visão cristã. Em outras culturas, como a japonesa, salienta Luc Benoist, em seu livro Signos, símbolos e mitos, Belo Horizonte, Interlivros, 1976, essa prodigalidade da água é expressa na lenda da terra sustentada por um peixe. $\mathrm{Na}$ Índia e na China, por uma tartaruga e entre os ameríndios, por uma serpente.

${ }^{11}$ Maria do Carmo Coelho, Elementos míticos no Minossauro, Brasilia, Editora da Universidade de Brasília, 1983, pp. 105-106.

${ }^{12}$ Buarque de Holanda, op. cit., p. 135. 
aqui "habitou até o tempo do Dilúvio Universal". Noé fez sua arca "na vertente ocidental da Cordilheira dos Andes com cedros e madeiras fortes. Tinha, segundo o Gênesis, ${ }^{13} 300$ côvados de comprido, 50 de largo e 30 de alto". ${ }^{14}$

Entretanto, o autor ressalta que são várias as visões do paraíso. A maioria nasceu na Idade Média, correspondendo a uma cosmogenia e paisagens idílicas e venturosas. Correspondia a uma espécie de resposta aos desejos e frustrações dos homens. Não é à toa, portanto, que o auge desse imaginário ocorreu no cenário histórico medieval, um período detentor de uma visão religiosa tenebrosa e psico-totalitária.

Além da religião, esse ideário idílico e paradisíaco povoou ainda a poesia e a literatura, a exemplo de $A$ Odisséia, de Homero, onde se lê que "naqueles lugares abençoados não se conhece a neve, nem o furacão hibernal, ou as grossas trovoadas. Apenas pode falar-se na amável viração que sopra das partes do Oeste. Levada com a água do mar: doce refrigério para os homens". ${ }^{15}$ Narrativas poéticas similares ressaltavam ainda a existência de ilhas onde jamais se conhecera a fome, nem a peste, os males que mais atemorizavam a humanidade no período medieval.

Entre as narrativas específicas sobre o Brasil, Buarque de Holanda destaca as de Américo Vespúcio e Cristóvam Colombo. O primeiro, mais sóbrio e objetivo, em uma carta intulada Bartolozzi, redigida em 1502, relata a abundância e o viço das plantas e flores nas matas brasileiras, bem como o suave aroma da flora e o sabor das frutas e raízes. A seu ver, são indícios da vizinhança do Paraíso Terreal. Em 1503, a carta seria reeditada com o nome de Mundus Novus, na qual o pensamento do cronista florentino se manifesta de forma bem mais enfática. ${ }^{16}$ Os relatos de Co-

13 Trata-se do primeiro livro da Bíblia, do Antigo Testamento, que relata a criação do mundo e o dilúvio.

${ }^{14}$ Buarque de Holanda, op. cit., p. 135.

${ }^{15}$ Aqui, Sérgio Buarque de Holanda cita um trecho da Odisséia, de Homero, IV, pp.563568 (ibid., p. 151).

${ }^{16}$ Aqui, Sérgio Buarque de Holanda reproduz, no original em italiano um amplo trecho de Mundus Novus, carta de Américo Vespúcio, de 1503, na qual ele faz um relato fan- 
lombo, por sua vez, mais efusivos e subjetivos, destacam a exuberância na natureza, a visão idílica e paradisíaca da terra recém-descoberta.

Outros cronistas contemporâneos a eles destacaram que a suposta longevidade dos índios fosse efeito dos bons céus, dos ares, das boas águas de que desfrutavam. Ademais, ressaltavam a ausência de pestes e enfermidades ou quaisquer outras influências nocivas à saúde dos nativos.

Diante do exposto, em uma tentativa de transpor essa "visão do paraíso" para um contexto mais recente, cabe destacar alguns elementos. $\mathrm{O}$ primeiro deles diz respeito à ordem discursiva instaurada e a seus agentes. Para isso, utilizaremos os conceitos de campo discursivo e formação discursiva de Michel Foucault. ${ }^{17} \mathrm{O}$ discurso ufanista produzido pelo Governo brasileiro constitui um ato de fala que produz e dá suporte a um regime de verdade que, mais do que representar ou documentar, tem o poder de construir e edificar visões de mundo, ordens de saber. Por meio desse discurso que os domínios de saber engendram práticas sociais de poder, que se estabelecem pela persuasão e por um consenso estabelecido.

Os enunciados do discurso oficial sobre ecologia são enunciados performativos e constatativos. Geralmente ressaltam tudo aquilo que o Governo realizou, realiza ou pensa em realizar. Ademais, apresenta constatações, sobretudo de caráter ufanista: a imensidão do território, a prodigalidade das águas, da fauna, da flora, das riquezas minerais. É nisso que consiste a função do discurso oficial sobre meio ambiente no Brasil, quando se trata da Amazônia: "na apreensão da linguagem em uso como um ato, que cria e sustenta regimes de verdade inerentes a estados de coisas e expectativas sociais". ${ }^{18}$

tástico sobre as paisagens da América, com destaque para as belezas e riquezas naturais. Sérgio Buarque de Holanda identifica na carta de Américo Vespúcio, descobridor da América, uma das fontes de fantasia sobre o paraíso tropical. A citação está na Buarque de Holanda, op. cit., p. 239.

${ }^{17}$ Michel Foucault, A Ordem do discurso, São Paulo, Loyola, 1996.

${ }^{18}$ Antonio Carlos Pereira, Atividades de interação verba e atos de fala, Brasilia, Thesaurus, 1999, p. 116. 
Assim, o discurso, entendido como prática social, na visão foucaultiana, deve ser compreendido a partir de sua gênese (condições de produção) que faz parte de um campo discursivo (todos os dados históricos válidos e vigentes em um certo intervalo de tempo) e de uma formação discursiva, isto é o conjunto de enunciados que se apresentam como pontos característicos de um saber.

O ufanismo constitui, portanto, uma prática discursiva que instaura um regime de verdade ancorado no mito da cosmogonia e no mito de Narciso, mas uma espécie de superlativo do mito de Narciso, ou seja, da nação brasileira, do povo brasileiro. É a natureza refletida na imensidão das águas, que se tornam espelho para a própria nação. Ou pelo menos é o que o discurso oficial brasileiro tenta destacar com seus enunciados performativos e constatativos, como nos exemplos acima destacados.

\section{A AMAZÔNIA NO DISCURSO PARA A COMUNIDADE INTERNACIONAL}

Os discursos de autoridades brasileiras nas assembléias-gerais da ONU constituem o expediente mais expressivo do discurso voltado para a comunidade internacional. Contudo, na década de 1970, os discursos das autoridades do Executivo Federal omitem a questão ambiental em si. Em outras palavras, o tema não aparece de forma expressiva e vigorosa. É mencionado apenas implicitamente, como corolário da abordagem de outros assuntos, como cooperação regional, soberania nacional e desenvolvimento. Nem mesmo em 1972, logo após a Conferência de Estocolmo, as autoridades brasileiras dedicaram atenção especial ao debate ecológico. Talvez a razão para tal omissão esteja no mal-estar causado pela posição brasileira, na Suécia, ao defender que a poluição era inerente à industrialização e que a miséria era pior do que a degradação ambiental.

Na década de 1980, o discurso oficial rejeita a responsabilidade exclusiva sobre a devastação ambiental e depois admite a devastação na Amazônia. Mas, em seguida, em tom ufanista, exalta a profusão de recursos e belezas naturais brasileiros: "mais do que ninguém, tem o Brasil 
consciência de sua exuberância, rica e extraordinária natureza. Suas florestas, sua fauna e sua flora são um patrimônio e uma riqueza que não abdicamos de preservar". Ao mesmo tempo, enfatiza o papel histórico do Brasil na preservação da natureza e opositor às empreitadas colonizadoras do "mundo rico" na África, Ásia e América:

o Brasil não as aceitou. Proibiu sua presença. Nos anos 60, o Instituto Hudson concebeu um grande lago para inundar a Amazônia. O Brasil repeliu-o. Se o mundo hoje pode voltar suas vistas para a Amazônia é porque os brasileiros souberam conservá-la até agora e o farão para o futuro.

Assim, o discurso oficial sobre meio ambiente, voltado para a comunidade internacional, perpassa a década de 1980, sem grandes alterações em relação à década anterior. A ecologia só é mencionada de forma circunstancial, seja para defender a posição do Governo brasileiro acerca do uso de recursos naturais compartilhados, seja para defender-se das pressões da opinião pública internacional.

Na década de 1990, todos os textos pertinentes aos eventos promovidos pela onu enfocam a Eco 92. A categoria Amazônia não é contemplada.

\section{O discurso para a comunidade internacional em fóruns de cooperação regional}

Causa da grande pressão internacional relativa à degradação ambiental no Brasil, a Amazônia é também o grande eixo propulsor do discurso oficial sobre meio ambiente, endereçado à comunidade internacional. O Tratado de Cooperação Amazônica, assinado em 3 de julho de 1978 é a locomotiva da produção discursiva do Governo brasileiro. Afinal, o Tratado foi assinado em 1978, mas a negociação tomou quase toda a década de 1970, uma vez que a concertação política entre os países, comandada pelo Brasil, foi decorrência da Conferência de Estocolmo, em uma tentativa de demonstrar à ONU e aos países desenvolvidos que o Brasil não era um "inimigo da ecologia". Assinaram o Tratado, além do Brasil, Colômbia, Equador, Guiana, Peru, Suriname e Venezuela. 
Demasiadamente ambicioso, no discurso de saudação aos chanceleres dos países citados, o então presidente Ernesto Geisel disse que, o Pacto Amazônico fazia "nascer para a História, uma nova Amazônia, destinada a ser terra de encontro e de colaboração entre povos da América". ${ }^{19}$ Objetivamente, o Tratado tinha como princípios fundamentais:

1 - A competência exclusiva dos países da Região no desenvolvimento e proteção da Amazônia;

2 - a soberania nacional na utilização e preservação dos recursos naturais e a conseqüente prioridade absoluta do esforço interno na política de desenvolvimento das áreas amazônicas de cada Estado;

3 - a cooperação regional como maneira de facilitar a realização desses objetivos;

4 - o equilíbrio e a harmonia entre o desenvolvimento e a proteção ecológica [grifo nosso];

5 - a absoluta igualdade entre todos os parceiros. ${ }^{20}$

Como se vê, o tema ecologia aparece sob a genérica rubrica de proteção ecológica. Mas, o que significa isso? Apenas uma forma intencional e estratégica de incluir o assunto, como resposta às pressões internacionais? É o que parece, pois, em todos os documentos examinados, essa "proteção" ambiental na Amazônia tende a constituir mero mecanismo de retórica.

O desenvolvimento amazônico é a outra categoria constantemente mencionada, mas nunca definida com precisão; sempre utilizada como termo genérico. O que significa desenvolver a Amazônia? Qual é o sentido desse desenvolvimento? Em que consiste? Como será efetivado? Quais seus efeitos práticos? São questões que os discursos não pareciam responder e nem sequer indicar pistas.

A exaltação às belezas e riquezas da Amazônia é outra tônica do discurso oficial:

${ }^{19}$ Brasil, Ministério das Relações Exteriores, Tratado de Cooperação Amazônica, Brasília, 1978a, p. 6.

${ }^{20}$ Brasil, Ministério das Relações Exteriores, Resenha de politica exterior do Brasil, vol. 6, núm. 21, Brasília, marzo-junio, 1979a, p. 5. 
[...] num mundo em que advertências responsáveis sensibilizam para a perigosa redução dos recursos naturais, a Amazônia apresenta-se com opulência de elementos vitais ao desenvolvimento e à própria sobrevivência. [...] água, energia, terra, trindade básica a que se podem acrescentar a madeira e os minérios, representam os dados brutos que falam eloqüentemente da viabilidade da Amazônia como projeto. E, articulando esses elementos uns aos outros e com o oceano, a mais completa das redes de caminhos fluviais.

[...] é natural e lógico o interesse brasileiro na cooperação amazônica, dada a atenção prioritária que o Brasil sempre dedicou à Amazônia, região que constitui a parcela mais extensa de seu patrimônio territorial e de recursos. Natural, também, é a receptividade dos parceiros amazônicos, que conosco compartilham a esperança de que o maior espaço tropical do mundo servirá, um dia, de base à grande e original civilização antecipada por Humboldt. [grifos nossos] ] $^{21}$

É por tudo isso que a Amazônia é vista como "uma região ainda por descobrir", ${ }^{22}$ tantas são suas riquezas e potencialidades, ressaltadas continuamente pelas autoridades brasileiras. Percebemos, assim, a presença do mito do paraíso terreal, sobretudo quanto à cosmogonia. Mas a conotação está mais no sentido de recriação desse mundo amazônico, tantas são as suas pontencialidades, apontadas pelo discurso oficial.

$\mathrm{Na}$ década de 1980, o Tratado de Cooperação Amazônica continua sendo a locomotiva do discurso oficial sobre ecologia, dirigido para a comunidade internacional, em âmbito regional. $\mathrm{O}$ pronunciamento do então presidente João Figueiredo, na I Reunião de Chanceleres dos Países do Tratado de Cooperação Amazônia segue a mesma trilha da década anterior: exaltação dos potenciais de riqueza natural e diversidade ecológica; a defesa da soberania; a atribuição da culpa pela devastação ambiental aos países desenvolvidos e a reafirmação do argumento de que o homem "é o agente beneficiário do desenvolvimento amazônico". ${ }^{23}$

${ }^{21}$ Brasil, Ministério das Relações Exteriores, Resenha de politica exterior do Brasil, vol. 5, núm. 18, Brasilia, junio-septiembre, 1978b, p. 9.

${ }^{22}$ Loc. cit.

${ }^{23}$ Brasil, Ministério das Relações Exteriores, Resenha de politica exterior do Brasil, vol. 17, núm. 27, Brasília, octubre-diciembre, 1980b, p. 27. 
A novidade é a abertura do leque de categorias relacionadas com o assunto, como: (1) acesso a tecnologias ambientais; (2) política ambiental; (3) qualidade de vida e (4) desarmamento nuclear. Como já esclarecemos são categorias mencionadas nos discursos e relacionadas com a temática em foco; não apresentam autonomia no contexto dos discursos e documentos oficiais sobre ecologia. São temas que são mencionados circunstancialmente. No caso da primeira, o tom é reivindicatório.

Existe ainda um tom inovador na exaltação da Amazônia, destacando, dessa vez, sua vocação para unir os países da América Latina entre si e com as demais nações do mundo tropical". É por isso que, segundo o Presidente,

temos de criar a ciência e desenvolver a tecnologia adequada às condições climáticas, do solo e da ecologia, no trópico úmido e ao longo da linha do equador. Só nós, os países amazônicos, poderemos fazê-lo. Sem desprezar a cooperação de cientistas de outras latitudes, temos de reconhecer que a experiência é aqui. As nações desenvolvidas não têm lições a dar-nos em matéria tropical [grifos nossos]. Temos de inventar e aperfeiçoar, como já estamos fazendo, técnicas e métodos de baixo custo, nascidos da própria realidade regional. Sem sofisticações inúteis. Utilizando matérias-primas locais. Mas, sobretudo, com uso intensivo de nosso recurso mais abundante: o trabalho criador de nossa gente. ${ }^{24}$

Convoca ainda todos os países do Pacto Amazônico a oferecer sua contribuição no campo da c\&t para a preservação ambiental, destacando o que o Brasil pode oferecer, com o Instituto Nacional de Pesquisas da Amazônia (INPA) e o Instituto Brasileiro de Desenvolvimento Florestal (IBDF), considerando sobretudo a questão florestal, pois, "nesse campo das florestas tropicais, é urgente que os países amazônicos façam frente comum contra as tentativas, alheias à Região, de impor limitações abusivas e ilegítimas ao direito inalienável desses países ao aproveitamento soberano e responsável de suas florestas, em benefício de seus próprios povos". ${ }^{25}$

\footnotetext{
${ }^{24}$ Ibid., p. 23.

${ }^{25}$ Ibid., p. 29.
} 
Quanto à posição do Brasil, especificamente, a respeito desse item, diz o mesmo discurso que

não considero necessário sacrificar nossa reserva florestal para fazer agricultura e pecuária. Nem admito que o progresso seja feito a custo do esmagamento do nosso ecossistema, do equilíbrio natural que Deus decretou para este pedaço majestoso do mundo. Nosso desenvolvimento deverá ser realizado com o mínimo irredutível de ofensa à natureza.

Na mesma linha de raciocínio, prossegue:

o que buscamos é promover o desenvolvimento da Região. Harmonioso. Pleno. Auto-sustentável. Integrado ao processo global de expansão das economias nacionais de cada um dos nossos países. Esse é nosso esforço. Isso procuramos tornar realidade no Brasil. Adotamos umapolítica de incentivos fiscais destinada a acelerar o desenvolvimento da Amazônia. Promovemos a abertura de estradas. Cada uma delas estende-se por milhares de quilômetros e oferece à agropecuária milhões de hectares de terras novas. ${ }^{26}$

Ressalta ainda a "colonização espontânea" de Rondônia como alternativa de desenvolver a região sem agredir a natureza e o potencial energético como outra opção de desenvolvimento, pois:

à medida que se esgota a energia fóssil, a Amazônia oferece fontes literalmente inesgotáveis de biomassa. Ou seja, de conversão da energia solar em combustíveis, através da fotossíntese. Álcool, metanol, óleos e outros sucedâneos do petróleo podem ser aqui obtidos, hoje, a custos compensadores. ${ }^{27}$

A cooperação regional como instrumento para o desenvolvimento foi o eixo dos discursos de 1983, embora nada mais tenha sido dito a respeito da operacionalização de tal cooperação e desse desenvolvimento. O discurso do chanceler brasileiro na II Reunião de Chanceleres do Tratado de Cooperação Amazônica apresenta um tom genérico do início ao fim:

\footnotetext{
${ }^{26}$ Loc. cit.

${ }^{27}$ Loc. cit.
} 
interpretando as aspirações e a determinação das populações amazônicas, nossos Governos buscam, com o Tratado de Cooperação Amazônia, dar uma moldura institucional ao processo de desenvolvimento que começou a ganhar força a partir da própria região;

reconhecemos na Amazônica mais uma de tantas áreas de coincidência de interesses entre nossos países e transformamos o desafio amazônico, comum a nossos povos, em fator de aproximação diplomática e política, com um setido de cooperação que se vem somar ao já expressivo potencial das relações bilaterais;

cumpre-nos igualmente aperfeiçoar a identificação de prioridades no esforço regional de cooperação;

acredita meu Governo que o presente encontro tem uma importância múltipla tanto para as políticas amazônicas [...] como para a cooperação multilateral. $^{28}$

Na reunião de 1985, o chanceler brasileiro limitou-se a analisar a conjuntura econômico-financeira da época de assinatura do Tratado e mencionar os documentos assinados nas reuniões anteriores. $\mathrm{O}$ assunto adquire maior vulto em 1989, com a Reunião dos Presidentes dos Países da Região Amazônica e a I Reunião da Comissão Especial de Meio Ambiente do Tratado de Cooperação.

Contudo, apesar dos longos discursos, tem-se a impressão de estar diante de uma reedição dos textos anteriores. Repetem-se exaustivamente os argumentos que fazem apologia à riqueza, beleza e diversidade natural da região, bem como os instrumentos governamentais paraassegurar o desenvolvimento da região, a cooperação regional e a preservação ecológica

\section{O discurso para o Brasil - outros documento}

A ecologia aparece sempre circunstancialmente no discurso oficial voltado para o Brasil. Isso revela que o Governo brasileiro ainda tratava o

${ }^{28}$ Brasil, Ministério das Relações Exteriores, Resenha de politica exterior do Brasil, vol. 20, núm. 39, Brasília, octubre-diciembre, 1983, pp. 91-93. 
assunto como marginal; parte de um tema mais importante - a tecnologia. Aliás, o objetivo do discurso era alertar para a necessidade de o país desenvolver tecnologia para evitar o desperdício de recursos naturais e implantar uma racionalidade econômica capaz de impedir a poluição ambiental. A essência do argumento é econômica, pois, como se lê no trecho sublinhado, tanto o desperdício de recursos como a poluição constituem elementos que "tolhem o nosso desenvolvimento econômico".

Quanto ao Tratado Amazônico, diiferentemente do discurso para a comunidade internacional as autoridades abordam principalmente os aspectos ligados à questão amazônica. $\mathrm{O}$ caráter inóspito, agravado pela muralha da Cordilheira dos Andes, favoreceu a criação de uma "civilização de periferia, descontínua e esparsa". Ademais, o "tempo amazônico era sem pressa. Regia-se não pelo homem mas pela lentidão dos ciclos biológicos e pelos mitos do 'Cobra Norato' ". ${ }^{29}$

A construção de Brasília é citada como um marco para a mudança nesse "tempo amazônico". Afinal,

Brasília veio perturbar essa modorra. Depois da falsa arrancada da borracha, foi a iniciativa política de interiorizar em Brasília o centro das decisões nacionais que lançou a Amazônia no século 20. A transferência da capital operou a revolução psicológica que atraiu a atenção do país para os cerrados e para a Amazônia. Sua primeira conseqüência foi a colonização espontânea da Belém-Brasília por centenas de milhares de brasileiros. ${ }^{30}$

\section{O texto prossegue, exaltando as iniciativas governamentais:}

o marco seguinte no processo de transformação ocorreu em 1976 com a adoção da política de incentivo fiscais e a organização da SUDAM, seguidas mais tarde pela ressurreição de Manaus, com a Zona Franca. Pela primeira vez, a abordagem dos problemas amazônicos se faria com continuidade e de acordo com filosofia radicalmente nova. Não mais os equívocos

${ }^{29}$ Brasil, Ministério das Relações Exteriores, Resenha de politica exterior do Brasil, vol. 6, núm. 21, Brasília, marzo-junio, 1979a, p. 72.

${ }^{30}$ Loc. cit. 
passados de uma economia ilusória e frágil, vulnerável às oscilações dos mercados externos e aos ciclos da economia mundial, mas um desenvolvimento harmonioso de todos os setores, auto-sustentável e integrado ao resto do país. Foram etapas desta fase a implantação de mais de 500 projetos pela SUDAM, a abertura das rodovias pioneiras e a colonização acelerada de Rondônia, as descobertas, através do RUDAM e outras pesquisas, do alumínio de Trombetas, do ferro e ouro de Carajás, a revelação de que as águas do Xingu, do Tocantins, do Tapajós escondem o pontencial energético de várias Itaipus, a realidade de Tucuruí e do Polamazônia.

Essas transformações vieram a criar, internacionalmente, a condição básica para que se pudesse pensar em propor uma cooperação mais ampla aos países da área. Pela primeira vez, o Brasil teve uma política definida para a Amazônia [grifos nossos] e, em conseqüência, teve a seu alcance, para partilhar com os vizinhos, não apenas o marasmo e a frustração de 30 anos atrás, mas um acervo concreto de experiências e de realizações, um receituário de fórmulas e técnicas de desenvolvimento regional, merecedoras de estudo, e quem sabe, de possível aplicação em condições similares. ${ }^{31}$

Os problemas da Amazônia praticamente são esquecidos. Importa destacar os avanços e as transformações. Assim, a região deixa de ser um assunto-problema para tornar-se fonte de positividade e onirismo, como: a "abordagem dos problemas com continuidade e de acordo com filosofia radicalmente nova" e "pela primeira vez, o Brasil teve uma política definida para a Amazônia”. No entanto, o Governo não caracteriza objetivamente essa filosofia, nem a política mecionada.

A questão indígena também aparece em um discurso do Ministro do Interior de 1978, Maurício Rangel Reis. Inicialmente, exalta a capacidade de convivência racial pacífica da sociedade brasileira, apontando como causa a miscigenação e a forte presença de estrangeiros na formação do país. Destaca ainda a "ausência de preconceitos" e a "igualdade de condições para a ascensão social”. O índio só aparece na última parte do discurso, apontado como "quem mais ficou, ao longo dos anos, à margem da sociedade brasileira, sem verdadeira possibilidade de completa integração". ${ }^{32}$

${ }^{31}$ Ibid., p. 73.

${ }^{32}$ Brasil, Ministério das Relações Exteriores, Relatório Anual, Brasília, 1978, p. 21. 


\section{Entretanto, logo aponta a solução encontrada pelo Governo}

a Constituição Federal e o Estatuto do Índio (Lei No. 6.001/73) determinam a "progressiva integração do índio à comunhão nacional", assegurados seus hábitos e costumes. Por outro lado, a legislação deixa claro o direito dos ídios à posse permanente e ao usufruto exclusivo das terras que ocupam ou habitam. Essa é, basicamente, a política indigenista brasileira.[grifos nossos]. ${ }^{33}$

Diante do último enunciado da citação acima cabe questionar: afinal, a política indigenista brasileira se resume a dois instrumentos legais de defesa do índio? É o que o discurso sugere. Além do mais, o fato de a legislação "determinar a progressiva integração do índio à sociedade" pode ser considerado realmente uma solução? A obrigação nunca é suficiente para garantir a aceitação de uma regra ou êxito de uma lei. Além da obrigação, toda norma social requer outro elemento: o desejo, a vontade de ver esta regra em vigência e o reconhecimento da sociedade de que a mesma é necessária. ${ }^{34}$

Enfim, a voz tímida do Governo sobre ecologia é ainda mais inibida quando se trata de falar para a nação. É o que se observa na década de 1970. Posteriormente, com a análise das décadas subseqüentes, aprofundaremos tal lacuna.

Na década de 1980, o "Programa Nossa Natureza" foi o único assunto objeto do discurso dirigido à população brasileira, nos outros documentos examinados (além do III PND e III PDCT), sob a forma de pronunciamento do Presidente José Sarney, na solenidade de lançamento do Programa, entendido como "um elenco de medidas substanciais" para a "reestruturação" do sistema governamental de controle e preservação do meio ambiente. Ademais,

o Programa é inédito no mundo. Não tem similar. Estamos com ele pronto, através de ações conjugadas, amplas e gerais, reformulando legislação,proce-

${ }^{33}$ Loc. cit.

${ }^{34}$ Émile Durkheim, Sociología e filosofía, São Paulo, Forense, 1970. 
dimentos, engajando recursos materiais e humanos num mutirão fantástico para defender o grande patrimônio de nossa fauna e de nossa flora. ${ }^{35}$

A Amazônia é o eixo do discurso, relacionada principalmente com a questão da soberania nacional. É um discurso dirigido ao público interno, mas soa como se fosse uma resposta às pressões internacionais:

a Amazônia é nossa. Nós é que a conhecemos melhor. Afinal ela está situada em nosso território;

o Brasil é nosso, a Amazônia é nossa, a natureza é nossa. O dever de preservá-la é dos brasileiros;

aceitamos ajuda internacional, mas não podemos aceitar condicionalidades, porque estas condicionalidades não são em favor da natureza, mas contra a natureza, porque visam à exploração e não à conservação e à preservação. Porque elas exploram o homem na mais abjeta de todas as poluições, que é a poluição da pobreza. ${ }^{36}$

Os demais aspectos do discurso ressaltam os benefícios do Programa, apontado como fruto do amadurecimento político-ambiental do Brasil desde a Conferência de Estocolmo. Os benefícios relacionam-se com a evolução da consciência ecológica nacional, do reconhecimento por parte do Governo da necessidade de qualificação de recursos humanos, do investimento em c\&t para o meio ambiente, da demarcação de áreas indígenas, da criação de parques nacionais e reservas ecológicas, bem como do debate sobre meio ambiente e reforma agrária.

O discurso direcionado para a sociedade brasileira, no ano de 1990, limita-se à categoria política indigenista, fruto de uma visita do então Presidente Fernando Collor de Melo ao Parque Indígena do Xingu, em janeiro de 1991. O texto é marcado por afirmações que idealizam o caráter e a cultura do índio brasileiro, tal qual nos poemas de Gonçalves Dias e nos romances de José de Alencar. Eis alguns trechos:

${ }^{35}$ Brasil, Ministério das Relações Exteriores, Resenha de politica exterior do Brasil, vol. 26, núm. 61, Brasília, abril-junio, 1989b, p. 11.

${ }^{36}$ Ibid., pp. 15-17. 
os povos indígenas contribuíram de forma decisiva na formação histórica e cultural do homem brasileiro. Seu legado vai muito além das palavras sonoras que enriqueceram a língua portuguesa, de hábitos alimentares e sociais incorporados a nosso cotidiano, do próprio sangue amalgamado ao povo brasileiro;

o índio ensinou nossos antepassados a conhecer a floresta tropical e os rios que cortam nosso território. Seus mitos e visões de mundo estão na base de nosso folclore e cultura popular. Seu conhecimento da fauna e da flora iluminou as pesquisas de muitos cientistas, farmacólogos e médicos;

o mais importante é que os índios continuam a ensinar o homem contemporâneo. E talvez essas lições sejam o mais perfeito símbolo de relevância de seus conhecimentos para toda a humanidade. Em sua simplicidade, nobreza e generosidade, o índio demonstra que a comunhão com a natureza é fonte de sabedoria e vitalidade. ${ }^{37}$

Tudo isso serve como preâmbulo para o Presidente enunciar a política indigenista de seu governo:

por isso, as diretrizes da política indigenista do meu Governo são e serão guiadas pelo respeito à identidade cultural, à promoção dos direitos humanos e pela promoção dos direitos humanos e pela garantia dos direitos de cidadania de todos os brasileiros, como determina a Constituição e exige um país moderno e democrático.

A tutela do estado deve garantir o exercício pleno dos direitos do cidadão indígena. ${ }^{38}$

Como isso será efetivado, parece não ser preocupação do Executivo Federal, que restringe-se a mencionar, como medida concreta, a demarcação de áreas indígenas, o que, sem dúvida não assegura, por si só, o respeito à identidade cultural e o "exercício pleno dos direitos do cidadão indígena". Para amenizar o tom evasivo do discurso, o Presidente diz que

o Estado não permanecerá insensível à tragédia vivida pelas comunidades cujas áreas se tornaram insuficientes para assegurar seu sustento. Trataremos

${ }^{37}$ Brasil, Ministério das Relações Exteriores, Resenha de política exterior do Brasil, vol. 18, núm. 68, Brasília, enero-junio, 1991b, p. 7.

${ }^{38} \mathrm{Ibid} .$, p. 8. 
de buscar, incessantemente, os meios de atender e remediar essa aflição que, infelizmente, é também a mesma de tantas famílias de outros brasileiros sem-terra, vítimas de desabrigo e órfãos de esperança [grifos nossos]. ${ }^{39}$

Com isso, o Governo ameniza a gravidade da questão indígena, equiparando-a aos demais problemas sociais, dos segmentos "descamisados". A especificidade do assunto em foco perde, assim, a sua força, tornando-se apenas mais um dos tópicos da agenda social brasileira. Trata-se de um modo ideológico de reduzir o impacto da tematização do assunto pelos meios de comunicação, pelos movimentos ambientalistas e pela sociedade.

\section{CONSIDERAÇÕES FINAIS}

A característica mais marcantes do discurso ecológico produzido no âmbito governamental, no período analisado, sobre a Amazônia brasileira é o ufanismo, que se manifesta na incessante exaltação dos atributos naturais do país. Tanto nos pronunciamentos em fóruns internacionais quanto nas ocasiões em que as autoridades se dirigem à sociedade brasileira, o tom ufanista é acentuado.

Trata-se de uma marca discursiva que é utilizada como estratégica política. A voz ufanista do Estado tenta obscurecer o tom denuncista dos organismos internacionais e governos estrangeiros e do movimento ambientalista brasileiro. Trata-se, pois, de um discurso estratégico, uma fala competente que se baseia no "agir-com-respeito-a-fins" de que fala Habermas, ${ }^{40}$ referindo-se a Max Weber. Assim, o discurso ecológico oficial institucionaliza um discurso sobre meio ambiente, apresentando-o como consenso mundial sobre o assunto. Este discurso estabelece efeitos de verdade, normas e princípios reguladores. Produz "um campo discur-

${ }^{39}$ Ibid., p. 9.

${ }^{40}$ J. Habermas, "Ciencia e técnica enquanto “ideología”, en W. Benjamín et al., Textos escolhidos, 2a ed., São Paulo, Abril Cultural, 1983, pp. 313-343. 
sivo englobante", dentro do qual devem abrigar-se grande parte dos discursos ecológicos. Contudo, por mais generalizante que sejam seus efeitos, marca um entendimento muito particular das questões ambientais. Na medida em que regulamenta, "fixa objetivos, estabelece princípios, produz o fato ecológico desde seu ponto de vista". ${ }^{41}$

Vale frisar que a emergência desse discurso remete à década de 1970, mais precisamente com a Conferência de Estocolmo, em 1972. Com isso, o Estado brasileiro viu-se obrigado a formular uma fala consensualizadora. Até então, o discurso de cientistas e ambientalistas era simplesmente ignorado pelas autoridades governamentais. Tal atitude do Governo brasileiro se deve ao fato de que foi nesta década que adquiriu força a preocupação com o impacto da produção industrial sobre a natureza, sobretudo por parte dos organismos internacionais sediados nos países centrais do capitalismo. Diversos valores passaram a ser questionados, como o consumismo, os estilos de vida nos grandes centros urbanos. O discurso oficial também incorporou essas críticas no seu vocabulário, só que, com outro interesse: produzir uma contra-argumentação, oferecendo "soluções onde se reconciliam preservação, qualidade de vida e crescimento industrial". ${ }^{42}$

Para consolidar tal estratégia discursiva, o Estado utiliza em seu vocabulário termos que sensibilizam a opinião pública, tais como desenvolvimento, soberania e autodeterminação. E em nome de conceitos portadores de uma generalidade estratégica, o Estado afirma e reafirma sua fala consensual institucionalizada, que estabelece efeitos de verdade e "produz o fato ecológico desde seu ponto de vista". ${ }^{43} \mathrm{Com}$ isso, o referido discurso, em termos operacionais, "procura equacionar preservação ambiental e qualidade de vida com o desenvolvimento industrial, dentro dos moldes capitalistas". ${ }^{4}$

\footnotetext{
${ }^{41}$ Carvalho, op. cit., p. 235.

42 Ibid., p. 236.

${ }^{43}$ Ibid., p. 235.

${ }^{44}$ Loc. cit.
} 
Essa concepção é reforçada pelo tom de generalidade do discurso oficial, sem um referente social específico. Ora o Governo fala da Amazônia, ora do índio, ora da população e da devastação, mas, mesmo quando trata de sistuações específicas, estrategicamente, opera, em termos discursivos, no plano do genérico, como se o ecologismo não tivesse referências históricas, sociais e econômicas. Com isso o Estado isenta a si mesmo de grande parte da responsabilidade na devastação ambiental que, historicamente, tem assolado todas as regiões brasileiras, sobretudo a Amazônia.

Finalmente, cabe ressaltarmos que o mito do paraíso terreal adquire diversas conotações e variações no discurso oficial brasileiro sobre a Amazônia. Além do tom laudatório e de vanglória desmedida, com base nas riquezas e belezas naturais da região, arrolamos ainda: (a) a visão onírica; (b) o ideal de progresso e desenvolvimento; (c) a idealização da cultura indígena; (d) o ideal de soberania do país "gigante pela sua própria natureza"; (e) o ideal de um futuro harmonioso, com desenvolvimento econômico e social, com melhor distribuição das riquezas.

Assim, o mito da cosmogonia remete a uma idéia de recriação do mundo paradisíaco na Amazônia. Uma estratégia discursiva que oculta uma realidade que remete mais ao mito do fim do mundo, no sentido escatológico, do que a essa conotação de recriação harmoniosa, presente no discurso oficial. 


\section{REFERÊNCIAS BIBLIOGRÁFICAS}

BARROS, Antonio T. de, Atores e discursos ecológicos no Brasil: ciência, estado e impresna (1972-92), Brasília, UNB, Departamento de Sociologia. 1999. (Tese de Doutoramento).

BENOIST, Luc, Signos, símbolos e mitos, Belo Horizonte, Interlivros, 1976.

BRASIL, Ministério das Relações Exteriores, Relatório Anual de 1972 do Ministério das Relações Exteriores, Brasília, 1972. , A Conferência de Estocolmo, Brasília, 1972. , Ministério do Interior, Declaração de Estocolmo, Brasília, 1972.

, Instituto Brasileiro de Geografia e Estatística, I Plano Nacional de Desenvolvimento (I PND), 1972-1974, Rio de Janeiro, 1971. 1975-79, Rio de Janeiro, 1974. , II Plano Nacional de Desenvolvimento (II PND), , Presidência da República, III Plano Nacional de Desenvolvimento (III PND), 1980-85, Brasília, 1980.

República, Brasília, 1986. , I Plano Nacional de Desenvolvimento da Nova , Instituto Brasileiro de Geografia e Estatística, II Plano Básico de Desenvolvimento Científico e Tecnológico (II PBDCT), 1975 1979, Rio de Janeiro, 1974.

, Ministério do Interior, Estação Ecológica do Taim, Secretaria Especial do Meio Ambiente, Brasília, 1975.

, Conselho Nacional de Desenvolvimento Científico e Tecnológico, III Plano Básico de Desenvolvimento Científico e Tecnológico (III PBDCT), 1980-1985, Brasília, 1980.

, Ministério das Relações Exteriores, Tratado de Cooperação Amazônica, Brasília, 1978a.

, Presidência da República, O Desafio do Desenvolvimento Sustentável: Relatório do Brasil para a Conferência das Nações Unidas sobre Meio Ambiente e Desenvolvimento, Brasília, 1991a. 
, Ministério das Relações Exteriores, Resenha de politica exterior do Brasil, vol.1, núm. 1, Brasília, marzo-junio, 1974a. . vol. 1, núm. 2, julio-septiembre,1974b.

. vol. 3, núm. 5, marzo-junio, 1975. . vol. 4, núm. 15 , octubre-dicie-

bre, 1977.

, Relatório Anual, Brasília, 1978. , vol. 5, núm. 18, julio-septiembre,

$1978 b$.

1978c.

, vol. 5, núm. 19, octubre-diciembre,

1979a. , vol. 6, núm. 21, marzo-junio,

$1979 b$. , vol. 6, núm. 22, julio-diciembre,

bre, 1980a. , vol. 17, núm. 26, julio-septiem-

bre, 1980b. , vol. 17, núm. 27 , octubre-diciembre, 1983. , vol. 20, núm. 39, octubre-diciem, vol. 21, núm. 41, abril-junio,

1984a.

bre, $1984 b$. , vol. 21, núm. 42, julio-septiem, Edição Suplementar, noviembre,

1985. , Resenha de Politica Exterior do Brasil, Brasília, vol. 24, núm. 54, julio-septiembre, 1987. , vol. 26, núm. 60, enero-marzo, 1989a. 
1989b.

, vol. 26, núm. 61, abril-junio,

bre, $1989 \mathrm{c}$.

, vol. 26, núm. 63, octubre-diciem-

1990a. $1990 \mathrm{~b}$. , vol. 27, núm. 66, julio-septiembre, 1991b. 1991c. 1992. , vol. 18, núm. 68, enero-junio, , vol. 18, núm. 19, julio-diciembre, , vol. 19, núm. 70, enero-junio, do Ministro Celso Lafer no Itamaraty, Brasília, 1993. , Instituto Nacional de Pesquisas e Estudos Educacionais, Desenvolvimento e educação ambiental, Brasília, 1992. , Presidência da República, Discursos de política externa I, Brasília, 1993.

, _ _ Discursos de política externa II, Brasília, 1994a. , Ministério das Relações Exteriores, A política externa do governo Itamar Franco, Brasília, Fundação Alexandre de Gusmão, 1994b.

, , Política externa em tempos de mudança: a gestão do Ministro Fernando Henrique Cardoso no Itamaraty, Brasília, Fundação Alexandre de Gusmão, 1994c. , A Palavra do Brasil nas Nações Unidas (19451995), Brasília, Fundação Alexandre de Gusmão, 1995. , Ministério do Interior, Programa Nacional de Meio Ambiente - Componente desenvolvimento institucional, Brasília, Ibama, 1989. 
CARVALHO, Isabel Cristina M., "Ecologia: um campo estratégico", Revista de Cultura Vozes, Petrópolis, vol. 84, núm. 2, marzo-abril, 1990, pp. 234-241.

COELHO, Maria do Carmo Pereira, Elementos Miticos no Minossauro, Brasília, Editora da Universidade de Brasilia, 1983.

CUNHA, Aércio S., "Desenvolvimento sustentável: a dimensão econômica", Humanidades, vol. 10, núm. 4, Brasília, 1996, pp. 322-329.

DURKHEIM, Émile, Sociologia e filosofía, São Paulo, Forense, 1970.

ELIADE, Mircea, O mito do eterno retorno, Coleção Perspectivas do Homem, Lisboa, Edições 70, 1969.

FOUCAULT, Michel, A ordem do discurso, São Paulo, Loyola, 1996.

FUKS, Mario, "Natureza e meio ambiente: a caminho da construção de um consenso social", en M. GOLDENBERG [org.], Ecologia, ciência e política, Rio de Janeiro, Renavan, 1992, pp. 121-34.

HABERMAS, J., "Ciência e técnica enquanto 'ideologia"”, en W. BENJAMIN et al., Textos escolhidos, $2^{\mathrm{a}}$ ed, São Paulo, Abril Cultural, 1983, pp. 313-343.

HOLANDA, Sérgio Buarque, Visão do paraíso: os motivos edênicos no descubrimento e civilização do Brasil, $2^{\text {a }}$ ed., São Paulo, Companhia Editora Nacional, 1969, 356 pp. [también edición de 1994].

MARTÍNEZ, Juan Alier, "Economia e ecologia: questões fundamentais”, Revista Brasileira de Ciências Sociais, vol. 3, núm. 7, São Paulo, junio, 1988, pp. 99-115.

PEREIRA, Antonio Carlos, Atividades de interação verba e atos de fala, Brasília, Thesaurus, 1999.

PESAVENTO, Sandra, Paraísos cruzados: diálogos do encantamento e do desencantamento do mundo (Gilberto Freyre e Sérgio Buarque de Holanda). Em http://www.unicamp.br/siarq/sbh/paraisos_cruzados.pdf. Consultado em 27.11.06 